\title{
Накопление зарядов в МОП-структурах с поликремниевым затвором при туннельной инжекции
}

\author{
(c) О.В. Александров, А.Н. Агеев, С.И. Золотарев \\ Санкт-Петербургский государственный электротехнический университет „ЛЭТИ“, \\ 197376 Санкт-Петербург, Россия \\ E-mail: Aleksandr_ov@mail.ru
}

(Получена 27 марта 2018 г. Принята к печати 10 апреля 2018 г.)

Изучено накопление зарядов в МОП-структурах с легированным и нелегированным поликремниевым затвором с Al-контактами и без них при тунннельной инжекции электронов из затвора и из кремниевой подложки. Показано, что независимо от полярности инжекции вблизи поликремниевого затвора накапливается отрицательный заряд, а вблизи кремниевой подложки положительный. При больших зарядах инжекции вблизи кремниевой подложки также появляется отрицательный заряд. Результаты описаны с помощью численной модели, в которой учтено образование электронных ловушек при нанесении Al-контактов и генерация электронных ловушек при рекомбинации свободных электронов с захваченными на ловушки дырками.

DOI: $10.21883 /$ FTP.2018.13.46877.8875

\section{1. Введение}

При подаче напряжения через МОП-структуру начинает протекать электронный туннельный ток ФаулераНортгейма $[1,2]$. При достаточно высокой напряженности электрического поля $(E>6-8 \mathrm{MB} / \mathrm{cm})$ в материале диэлектрика или анода происходит ударная ионизация и появляется дырочный ток [1,2]. Электроны и дырки захватываются на ловушки в объеме диэлектрика и на поверхностные состояния (ПС), приводя к накоплению заряда в МОП-структуре. Этот процесс приводит к перераспределению электрического поля в МОП-структуре, сдвигу порогового напряжения МОП-транзисторов, сдвигу напряжения затвора в режиме постоянного тока (или изменению тока в режиме постоянного напряжения), а также к изменению времени ожидания пробоя и в некоторых случаях к преждевременному пробою [3]. Накопление заряда зависит от типа и концентрации ловушек в объеме диэлектрика и на межфазных границах (МФГ), распределения их по толщине диэлектрика, а также от напряженности электрического поля, полярности и заряда инжекции электронов [4-6]. В предыдущей работе [7] нами изучалось и моделировалось накопление зарядов в подзатворном диоксиде кремния $n$ - и $p$-МОП-транзисторов при туннельной инжекции электронов из поликремниевого затвора (при $\left.V_{g}<0\right)$ с зарядом $\left(Q_{i n j}<0.3 \mathrm{Kл} / \mathrm{cm}^{2}\right)$ и напряженностью электрического поля $(E<8 \mathrm{MB} / \mathrm{cm})$ меньше максимально возможных. Сдвиг напряжения затвора в режиме постоянного тока объяснялся захватом инжектируемых электронов на исходные нейтральные ловушки вблизи затвора. Сдвиг порогового напряжения связывался с образованием дырок по механизму анодной дырочной инжекции и их захватом исходными водородосодержащими ловушками вблизи кремниевой подложки. В результате появлялись положительный заряд на безводородных ловушках и поверхностные состояния на МФГ $\mathrm{Si}-\mathrm{SiO}_{2}$.
Генерации новых ловушек в объеме $\mathrm{SiO}_{2}$ при этом не наблюдалось.

В ряде работ [8-11] при достаточно высоких зарядах туннельной инжекции электронов $\left(Q_{i n j}>0.1 \mathrm{Kл} / \mathrm{cm}^{2}\right)$ и напряженности электрического поля $(E>8 \mathrm{MB} / \mathrm{cm})$ после введения положительного заряда наблюдалось образование отрицательного заряда, который авторы объясняли генерацией новых электронных ловушек. Было предложено несколько механизмов их генерации [8-16]. В работах $[10,12]$ генерация электронных ловушек у катода связывалась с освобождением водорода вблизи анода под действием горячих электронов, его миграцией к катоду и взаимодействием водорода с оборванными связями оксидных ловушек вблизи катода. В работах $[8,11]$ образование электронных ловушек связывалось с ударной ионизацией $\mathrm{SiO}_{2}$ или ловушек при достаточно высоких полях $(E>10 \mathrm{MB} / \mathrm{cm})$. Показано, однако, что генерация электронных ловушек происходит даже при невысоких полях $(E>4 \mathrm{MB} / \mathrm{cm})$ при наличии дырок $[9,14]$ и что инжекция дырок является необходимым условием для генерации электронных ловушек [13-15]. В работах [9,13-15] генерация электронных ловушек объяснялась взаимодействием одних только дырок со структурой $\mathrm{SiO}_{2}$, разрывом напряженных связей $\mathrm{Si}-\mathrm{O}$ и образованием немостикового кислорода. В работе [16] предложен рекомбинационный механизм генерации электронных ловушек, учитывающий необходимость наличия как электронов, так и дырок. Согласно этому механизму [16], генерация электронных ловушек происходит при рекомбинации свободных электронов с дырками, захваченными на ловушки. При этом за счет выделившейся при рекомбинации энергии происходит структурная перестройка дефекта, разрыв связи и релаксация к другому дефектному состоянию. В настоящей работе изучается и моделируется накопление заряда в МОП-структурах с легированным фосфором и нелегированным поликремниевым затвором, с наличием 
и отсутствием Al-контактов при туннельной инжекции электронов как из затвора, так и из кремниевой подложки при инжектируемом заряде и электрическом поле, достаточными для генерации электронных ловушек.

\section{2. Эксперимент}

МОП-структуры изготавливались на пластинах монокристаллического кремния $n$-типа ориентации (100) с удельным сопротивлением 7.5 Ом.см. Окисление проводилось при температуре $1000^{\circ} \mathrm{C}$ в сухом кислороде с добавкой $1 \% \mathrm{HCl}$ в течение 40 мин. Толщина оксида составляла 120 нм. Поверх оксида газофазным методом наносился поликристаллический кремний (поликремний) толщиной 0.5 мкм. Поликремний легировался фосфором путем диффузии из газовой фазы при температуре $900^{\circ} \mathrm{C}$. После удаления фосфоросиликатного стекла с помощью фотолитографии формировались поликремниевые электроды (затворы), на которые с помощью следующей фотолитографии наносились Al-контакты. Последние вжигались при температуре $450^{\circ} \mathrm{C}$ в течение 30 мин в среде азота. Часть пластин оставлялась без легирования поликремния и без Al-контактов.

Измерялся сдвиг напряжения затвора $\Delta V_{g}$ в режиме постоянного тока $\left(I=10 \mathrm{HA}, j=1 \cdot 10^{-3} \mathrm{~A} / \mathrm{cm}^{2}\right)$ при отрицательной $\left(\Delta V_{g}^{-}\right)$и при положительной $\left(\Delta V_{g}^{+}\right)$полярностях после инжекции электронов как из затвора $\left(\right.$ при $\left.V_{g}<0\right)$, так и из подложки (при $\left.V_{g}>0\right)$. Начальное напряжение, подаваемое на затвор, составляло 90-110 В. Время инжекции $(t)$ ограничивалось пробоем МОП-структуры, а инжектируемый заряд $\left(Q_{i n j}=j \cdot t\right)$ достигал 1 Кл/см².

Сдвиг напряжения затвора в отрицательной полярности определяется зарядом вблизи затвора:

$$
\Delta V_{g}^{-}=\frac{1}{C_{o x} d} \int_{0}^{d} \rho(x) x d x,
$$

а в положительной полярности - зарядом вблизи кремниевой подложки

$$
\Delta V_{g}^{+}=-\frac{1}{C_{o x} d} \int_{0}^{d} \rho(x)(d-x) d x,
$$

где координата $x$ отсчитывается от кремниевой подложки, $d-$ толщина оксида, $\rho(x)$ - плотность объемного заряда, $C_{o x}$ - удельная емкость диэлектрика. Как было показано в [7], и положительный, и отрицательный заряды локализованы вблизи внутренней и внешней МФГ.

Изменение напряжения затвора в отрицательной полярности $\left(\Delta V_{g}^{-}\right)$на структурах с легированным поликремнием показано на рис. 1 после инжекции электронов из затвора (кривые 1,2) и из подложки (кривые 3,4 ) с Al (кривые 1,3) и без Al (кривые 2,4) контактов. Во всех случаях независимо от полярности инжекции

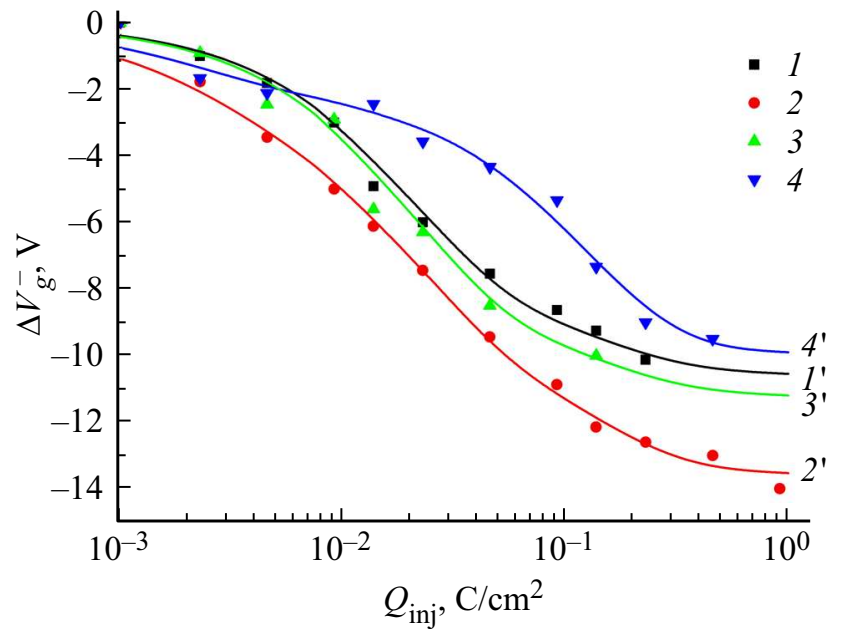

Рис. 1. Сдвиг напряжения затвора $\Delta V_{g}^{-}$на структурах с легированным поликристаллическим затвором после инжекции из затвора $(1,2)$ и из подложки $(3,4)$ с Al-контактами (кривые 1,3 ) и без Al-контактов (кривые 2, 4). 1-4 - эксперимент, $1^{\prime}-4^{\prime}-$ расчет.

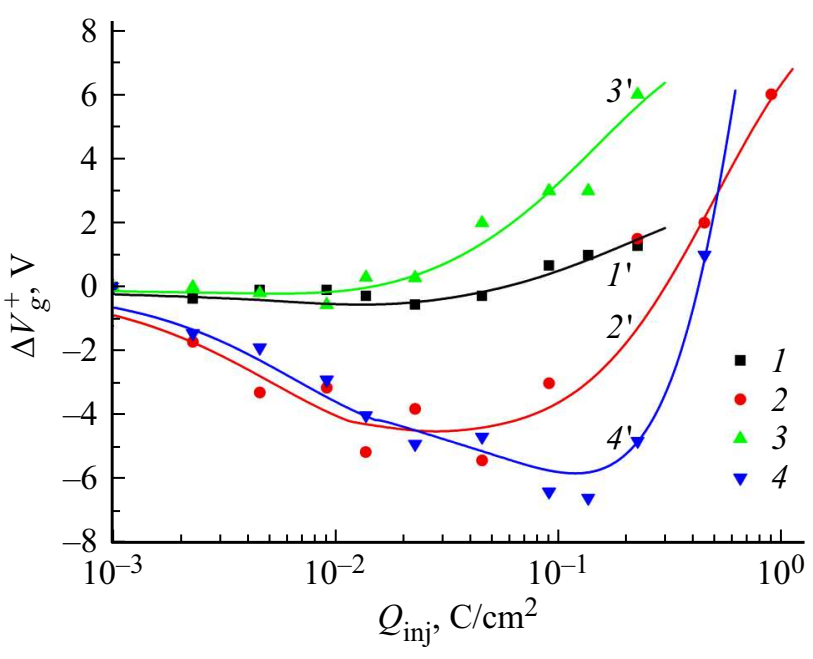

Рис. 2. Сдвиг напряжения затвора $\Delta V_{g}^{+}$на структурах с легированным поликристаллическим затвором после инжекции из затвора (кривые 1,2) и из подложки (кривые 3,4) с Al-контактами (кривые 1,3) и без Al-контактов (кривые 2, 4). $1-4$ - эксперимент, $1^{\prime}-4^{\prime}-$ расчет.

и наличия Al-контакта сдвиг $\Delta V_{g}^{-}$отрицателен и $\left|\Delta V_{g}^{-}\right|$ растет примерно линейно от $\log \left(Q_{i n j}\right)$. Отрицательный сдвиг $\Delta V_{g}^{-}$свидетельствует о накоплении отрицательного заряда в подзатворном оксиде вблизи затвора.

Изменение напряжения затвора в положительной полярности $\left(\Delta V_{g}^{+}\right)$на структурах с легированным поликремнием показано на рис. 2 после инжекции электронов из затвора (кривые 1,2) и из подложки (кривые 3, 4) с Al-контактами (кривые 1,3) и без Al (кривые 2,4). Как видно из рис. 2, на структурах без Al при малых зарядах инжекции наблюдается отрицательный сдвиг $\Delta V_{g}^{+}$(кривые 2,4), что свидетельствует о введении 


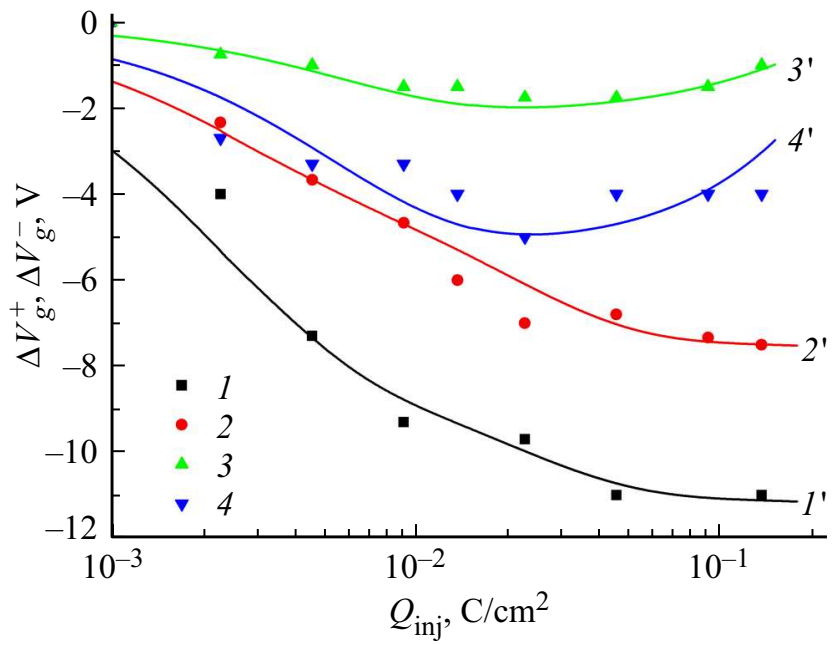

Pис. 3. Сдвиг напряжения затвора $\Delta V_{g}^{-}$(кривые 1,2$)$ и $\Delta V_{g}^{+}$ (кривые 3,4$)$ на структурах с нелегированным поликристаллическим затвором после инжекции из затвора с Al-контактами (кривые 1,3) и без Al-контактов (кривые 2,4). 1-4 - эксперимент, $1^{\prime}-4^{\prime}-$ расчет.

положительного заряда вблизи подложки. На структурах c Al при малых зарядах инжекции отрицательный сдвиг $\Delta V_{g}^{+}$мал. При больших зарядах инжекции во всех случаях наблюдается рост $\Delta V_{g}^{+}$, что свидетельствует о введении отрицательного заряда в подзатворный оксид вблизи подложки.

На структурах с нелегированным поликристаллическим затвором после инжекции из затвора наблюдается отрицательный сдвиг $\Delta V_{g}^{-}$(рис. 3, кривые 1,2 ) и отрицательный сдвиг $\Delta V_{g}^{+}$(кривые 3,4 ). Таким образом, имеем введение отрицательного заряда вблизи затвора и введение положительного заряда вблизи подложки соответственно. Отметим, что структуры с легированным поликремниевым затвором пробиваются при бо́льших зарядах инжекции при обеих ее полярностях $\left(Q_{b d}=0.3-1.0 \mathrm{Kл} / \mathrm{cm}^{2}\right)$, чем с нелегированным поликремниевым затвором как при инжекции из затвора $\left(Q_{b d}=0.2-0.3\right.$ Кл/см $\left.{ }^{2}\right)$, так и особенно при инжекции из подложки $\left(Q_{b d}=0.03-0.05\right.$ Кл/см $\left.{ }^{2}\right)$.

\section{3. Обсуждение экспериментальных результатов}

На структурах с легированным поликремниевым затвором наблюдается накопление отрицательного заряда вблизи затвора $\left(\Delta V_{g}^{-}<0\right)$ при всех зарядах инжекции как из затвора, так и из подложки (рис. 1, кривые $1-4$ ). Отрицательный заряд вводится также и при больших зарядах инжекции вблизи подложки $\left(\Delta V_{g}^{+}>0\right)$ (рис. 2, кривые 1-4). При малых зарядах инжекции вблизи подложки образуется положительный заряд $\left(\Delta V_{g}^{+}<0\right)$ (рис. 2, кривые 2,4). При этом полярность инжекции не оказывает заметного влияния на закономерности накопления заряда.

Причиной появления отрицательного заряда вблизи $n^{+}$-поликремниевого затвора является захват электронов, инжектируемых из затвора, на исходные ловушки в диоксиде кремния. При диффузионном легировании поликристаллического затвора фосфором такими ловушками могут являться атомы фосфора в тонком слое $\mathrm{SiO}_{2}$, примыкающем к затвору. Однако отрицательный сдвиг $\Delta V_{g}^{-}$наблюдается и на структурах с нелегированным поликремнием (рис. 3, кривые 1,2 ), т.е. с атомами фосфора не связан. Введение отрицательного заряда при инжекции электронов связывается обычно с их захватом на электронные ловушки, обусловленные присутствием фрагментов воды и гидроксильных групп ОН $[1,2,17-19]$. Концентрация таких ловушек, как правило, однородная по толщине оксида, имеет накопление на обеих МФГ [17]. В МОП-структурах с поликремниевым затвором наблюдаются также мелкие и глубокие электронные ловушки, обусловленные собственными дефектами $\mathrm{SiO}_{2}$, связанными с дефицитом кислорода [20,21]. Эти дефекты образуются при высокотемпературных обработках вследствие взаимодействия $\mathrm{SiO}_{2}$ с кремнием подложки и затвора.

На структурах с легированным поликремниевым затвором при положительной полярности инжекции выявляется влияние нанесения Al-контактов (рис. 2). При малых зарядах инжекции на структурах без Al-контактов наблюдается отрицательный сдвиг $\Delta V_{g}^{+}$(кривые 2,4), что соответствует введению положительного заряда вблизи подложки. Тогда, как и при наличии Al-контактов, отрицательный сдвиг $\Delta V_{g}^{+}$мал (кривые 1,3$)$, т. е. наличие $\mathrm{Al}$ приводит к подавлению положительного заряда вблизи подложки. Положительный заряд в $\mathrm{SiO}_{2}$ вблизи кремниевой подложки связывают с дырочными ловушками $\mathrm{E}^{\prime}$ - и $\mathrm{E}^{\prime} \mathrm{H}$-центрами в $\mathrm{SiO}_{2}[1,2]$. Можно предположить, что отрицательно заряженные группы $\mathrm{OH}^{-}$, образующиеся вместе с водородом при разложении молекул воды в присутствии Al [22,23], компенсируют положительный заряд $\mathrm{E}^{\prime}$ - и $\mathrm{E}^{\prime} \mathrm{H}$-центров, а при больших зарядах инжекции сами вносят отрицательный заряд. На структурах с нелегированным поликремнием влияние нанесения Al-контактов проявляется слабее (рис. 3, кривые 3,4). Возможной причиной этого является плохая проницаемость нелегированного поликремния для групп $\mathrm{OH}$ и водорода в отличие от легированного поликремния [24].

При больших зарядах инжекции наблюдается быстрый рост $\Delta V_{g}^{+}$(рис. 2, кривые 2,4), что свидетельствует о введении отрицательного заряда в МОП-структуры вблизи подложки. Введение сначала положительного заряда, а затем отрицательного при увеличении времени или заряда инжекции наблюдалось в ряде работ [8-11]. Такое поведение при малых зарядах инжекции объяснялось генерацией дырок при ударной ионизации оксида или материала анода и их захватом на дырочные ловушки. Введение отрицательного заряда при больших зарядах инжекции объяснялось генерацией 
Таблица 1. Полные концентрации исходных ловушек вблизи МФГ $\mathrm{Si}-\mathrm{SiO}_{2}$

\begin{tabular}{c|c|c|c|c|c|c}
\hline \multirow{2}{*}{$\begin{array}{c}\text { Полные } \\
\text { концентрации }\end{array}$} & \multicolumn{4}{|c|}{ Кривые рис. 2 } & \multicolumn{2}{c}{ Кривые рис. 3 } \\
\cline { 2 - 7 } & $1^{\prime}$ & $2^{\prime}$ & $3^{\prime}$ & $4^{\prime}$ & $3^{\prime}$ & $4^{\prime}$ \\
\hline$Q_{T 0}^{0}, \mathrm{~cm}^{-2}$ & $3.0 \cdot 10^{11}$ & $2.0 \cdot 10^{12}$ & $3.0 \cdot 10^{11}$ & $1.2 \cdot 10^{12}$ & $7 \cdot 10^{11}$ & $1.9 \cdot 10^{12}$ \\
$Q_{T H 0}^{0}, \mathrm{~cm}^{-2}$ & - & - & - & $3.9 \cdot 10^{12}$ & - & - \\
$Q_{S 0}^{0}, \mathrm{~cm}^{-2}$ & $4.2 \cdot 10^{11}$ & - & $1.5 \cdot 10^{12}$ & - & - & -
\end{tabular}

новых электронных ловушек [8-11]. Из всех предложенных механизмов генерации электронных ловушек [8-16] наиболее вероятным представляется рекомбинационный механизм, предложенный в работе [16], который требует наличия и электронов, и дырок. В этом механизме генерация нейтральных электронных ловушек происходит при рекомбинации свободного электрона с дыркой, захваченной на ловушку. За счет выделившейся при этом энергии рекомбинации происходит структурная перестройка дефекта из дырочной ловушки в электронную.

Структуры с нелегированным поликремнием при инжекции из подложки (при $V_{g}>0$ ) пробиваются при меньших временах и зарядах инжекции, чем при инжекции из затвора. Это связано, по-видимому, с накоплением положительного заряда вблизи катода-подложки (см. рис. 3, кривые 3,4). Как показано в [3], пробой МОП-структур связан с наличием дырочных ловушек вблизи катода и положительной обратной связью по мере их заполнения. Появление отрицательного заряда в МОП-структурах как с легированным, так и с нелегированным поликремнием, наоборот, способствует повышению напряжения пробоя.

\section{4. Расчеты по модели и их обсуждение}

К процессам накопления зарядов в МОП-структуре, происходящим в МОП-структуре при инжекции электронов, описанным нами ранее в модели [7], в нашем случае добавляются эффекты, обусловленные влиянием Al-металлизации, а также генерации электронных ловушек при высоких полях и больших зарядах инжекции.

Первый эффект связываем с введением гидроксильных групп ОН, образующихся при разложении молекул воды в присутствии Al [22,23]. Эти группы, заряжаясь отрицательно, компенсируют положительный заряд $\mathrm{E}^{\prime}$ -

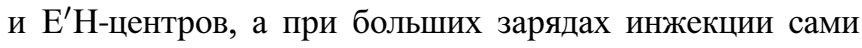
вносят отрицательный заряд. Учтем его путем введения исходных нейтральных электронных ловушек $S^{0}$ вблизи МФГ $\mathrm{Si}-\mathrm{SiO}_{2}$,

$$
S^{0}+e^{-} \stackrel{k 1}{\longrightarrow} S^{-}
$$

при существенном уменьшении полных концентраций дырочных ловушек $Q_{T 0}^{0}$ и $Q_{T H 0}^{0}$.

Второй эффект, обусловленный генерацией электронных ловушек, учтем в соответствии с рекомбинацион- ным механизмом [16] с помощью реакции преобразования части заполненных (положительно заряженных) безводородных дырочных ловушек $T^{+}$в нейтральные электронные при захвате свободных электронов:

$$
T^{+}+e^{-} \stackrel{k 2}{\longrightarrow} M^{0}
$$

где $M^{0}$ - нейтральные электронные ловушки, которые при последующем захвате электронов образуют отрицательный заряд вблизи подложки,

$$
M^{0}+e^{-} \stackrel{k 3}{\longrightarrow} M^{-} \text {. }
$$

В работах $[25,26]$ было показано, что процесс генерации электронных ловушек обратим, т. е. может быть неоднократно повторен путем изменения напряжения затвора или последовательной инжекции дырок и электронов. В рамках рекомбинационного механизма этот эффект обратимости может быть объяснен тем, что заполненные электронные ловушки $M^{-}$при захвате дырок за счет выделяющейся при рекомбинации энергии превращаются снова в нейтральные дырочные ловушки $T^{0}$, т.е. имеет место реакция

$$
M^{-}+h^{+} \stackrel{k 4}{\longrightarrow} T^{0} .
$$

Кинетические уравнения, соответствующие реакциям (1)-(4), добавляются к общей системе диффузионнокинетических уравнений модели [7]. В дополнительных реакциях (1)-(4) использованы следующие сечения захвата: $\sigma_{n S 1}^{0}=2.6 \cdot 10^{-17} \mathrm{~cm}^{2}[13], \sigma_{n 02}^{+}=2.1 \cdot 10^{-13} \mathrm{~cm}^{2}$ (в 7.7 раз меньше, чем в обычной реакции нейтрализации дырочной ловушки в [7]), $\sigma_{n 3}^{0}=6.0 \cdot 10^{-18} \mathrm{~cm}^{2}$ и $\sigma_{p 4}^{-}=5.0 \cdot 10^{-18} \mathrm{~cm}^{2}$. Полные концентрации исходных нейтральных электронных ловушек $Q_{S 0}^{0}$, безводородных $Q_{T 0}^{0}$ и водородосодержащих $Q_{T H 0}^{0}$ дырочных ловушек, обеспечивающие соответствие расчетных зависимостей $\Delta V_{g}^{+}\left(Q_{i n j}\right)$ (кривые $1^{\prime}-4^{\prime}$ на рис. 2 и кривые $3^{\prime}$ и $4^{\prime}$ на рис. 3) с экспериментальными данными, приведены в табл. 1 .

Как отмечалось в разд. 3, экспериментальные зависимости $\left|\Delta V_{g}^{-}\right|$примерно линейны от $\log \left(Q_{i n j}\right)$. Как показали расчеты, совокупность зависимостей такого вида может быть удовлетворительно описана захватом электронов на не менее чем три вида нейтральных центров $\left(R_{1}, R_{2}\right.$ и $\left.R_{3}\right)$ с разными сечениями захвата $\left(\sigma_{n R 1}^{0}<\sigma_{n R 2}^{0}<\sigma_{n R 3}^{0}\right)$ и разными полными концентрациями $\left(Q_{R 1}^{0}, Q_{R 2}^{0}\right.$ и $\left.Q_{R 3}^{0}\right)$. Максимальное и минимальное сечения определяют соответственно начало и конец роста $\left|\Delta V_{g}^{-}\right|$, а также вместе с $\sigma_{n R 2}^{0}$ и полными 
Таблица 2. Полные концентрации электронных ловушек вблизи $\mathrm{MФГ} \mathrm{SiO}_{2}$-поликремний

\begin{tabular}{c|c|c|c|c|c|c}
\hline \multirow{2}{*}{$\begin{array}{c}\text { Полные } \\
\text { концентрации }\end{array}$} & \multicolumn{4}{|c|}{ Кривые рис. 1 } & \multicolumn{2}{c}{ Кривые рис. 3 } \\
\cline { 2 - 7 } & $1^{\prime}$ & $2^{\prime}$ & $3^{\prime}$ & $4^{\prime}$ & $1^{\prime}$ & $2^{\prime}$ \\
\hline$Q_{R 1}^{0}, \mathrm{~cm}^{-2}$ & $4.0 \cdot 10^{11}$ & $6.6 \cdot 10^{11}$ & $4.0 \cdot 10^{11}$ & $1.2 \cdot 10^{12}$ & - & - \\
$Q_{R 2}^{0}, \mathrm{~cm}^{-2}$ & $1.2 \cdot 10^{12}$ & $1.1 \cdot 10^{12}$ & $1.3 \cdot 10^{12}$ & - & $5.3 \cdot 10^{11}$ & $6.7 \cdot 10^{11}$ \\
$Q_{R 3}^{0}, \mathrm{~cm}^{-2}$ & - & $3.0 \cdot 10^{11}$ & - & $3.0 \cdot 10^{11}$ & $1.2 \cdot 10^{12}$ & $5.0 \cdot 10^{11}$
\end{tabular}

концентрациями задают наклон зависимости $\left|\Delta V_{g}^{-}\right|$от $\log \left(Q_{i n j}\right)$. Суммарная полная концентрация электронных ловушек $\left(Q_{R}^{0}=Q_{R 1}^{0}+Q_{R 2}^{0}+Q_{R 3}^{0}\right)$ определяет величину насыщения $\Delta V_{g}^{-}$при больших зарядах инжекции. В качестве сечений захвата использовались значения, полученные в работе [13] при инжекции электронов в МОП-структурах с поликремниевым затвоpом: $\sigma_{n R 1}^{0}=\sigma_{n S 1}^{0}=2.6 \cdot 10^{-17} \mathrm{~cm}^{2}, \sigma_{n R 2}^{0}=1.6 \cdot 10^{-16} \mathrm{~cm}^{2}$, $\sigma_{n R 3}^{0}=1.4 \cdot 10^{-15} \mathrm{~cm}^{2}$. Полные концентрации электронных ловушек, обеспечивающие соответствие расчетных зависимостей $\Delta V_{g}^{-}\left(Q_{i n j}\right)$ (рис. 1 , кривые $l^{\prime}-4^{\prime}$ и рис. 3, кривые $1^{\prime}$ и $2^{\prime}$ ) с экспериментальными данными, приведены в табл. 2.

Как видно из рис. 1-3, расчетные зависимости удовлетворительно описывают экспериментальные данные. Используемые сечения захвата и найденные полные концентрации дырочных и электронных ловушек лежат в диапазоне литературных данных. Так, для электронных ловушек, связанных с присутствием фрагментов воды гидроксильных групп ОН, характерны сечения захвата $10^{-17}-10^{-18} \mathrm{~cm}^{2}[1,2]$. Сечения захвата электронных ловушек, обусловленных дефицитом кислорода, имеют более широкий диапазон значений $10^{-16}-10^{-19} \mathrm{~cm}^{2}$ [27]. В работах $[20,21,27]$ показана общая природа электронных и дырочных ловушек, обусловленная дефицитом кислорода в слоях $\mathrm{SiO}_{2}$, подвергнутых высокотемпературным обработкам.

Отметим, что в рамках рекомбинационного механизма [16] может быть объяснена обратимость генерации нейтральных электронных ловушек при последовательной инжекции дырок и электронов, показанная в $[25,26]$. Основными дырочными ловушками в $\mathrm{SiO}_{2}$ являются кислородные вакансии, которые при захвате дырок становятся положительно заряженными, так называемыми $\mathrm{E}^{\prime}$-центрами [1,2]:

$$
\mathrm{O}_{3} \equiv \mathrm{Si} \cdot \mathrm{Si} \equiv \mathrm{O}_{3}+h^{+} \rightarrow \mathrm{O}_{3} \equiv \mathrm{Si}^{+} \cdot \mathrm{Si} \equiv \mathrm{O}_{3} .
$$

При последующем захвате инжектируемых электронов, происходящем с выделением энергии рекомбинации и структурной перестройкой дефекта, помимо обычной нейтрализации кислородной вакансии могут образоваться фрагменты сетки с тривалентным кремнием $\mathrm{O}_{3} \equiv \mathrm{Si}$. Последние, как показано в [27], ведут себя как нейтральные электронные ловушки и захватывают на себя электроны. При последующей инжекции дырок снова происходит выделение энергии рекомбинации, структур- ная перестройка дефекта и восстанавливаются первоначальные нейтральные кислородные вакансии.

\section{5. Заключение}

Изучено влияние туннельной инжекции из затвора и подложки на накопление заряда в МОП-структурах с легированным фосфором и нелегированным поликремниевым затвором при наличии и отсутствии Al-контактов. Показано, что независимо от направления инжекции (из затвора или подложки) вблизи поликремниевого затвора накапливается отрицательный заряд, а вблизи подложки - положительный. При больших зарядах инжекции отрицательный заряд появляется также и вблизи подложки. Зависимости сдвига напряжения затвора от заряда инжекции описаны с помощью численной модели, в которой учтены образование электронных ловушек при нанесении Al-контактов и генерация электронных ловушек при рекомбинации свободных электронов с захваченными на ловушки дырками.

\section{Список литературы}

[1] Г.Я. Красников, Н.А. Зайцев. Система кремний-диоксид кремния субмикронных СБИС (М., Техносфера, 2003).

[2] А.П. Барабан, В.В. Булавинов, П.П. Коноров. Электроника слоев $\mathrm{SiO}_{2}$ на кремнии (Л., ЛГУ, 1988).

[3] О.В. Александров. ФТП, 51 (8), 1105 (2017).

[4] Y. Nissan-Cohen, J. Shappir, D. Frohman-Bentchkowsky. J. Appl. Phys., 57 (8), 2830 (1985).

[5] В.В. Андреев, В.Г. Барышев, Г.Г. Бондаренко, А.А. Столяров, В.А. Шахнов. Микроэлектроника, 26 (6), 440 (1997).

[6] Y.-B. Park, D.K. Schroeder. IEEE Trans. Electron. Dev., 45, 1361 (1998).

[7] О.В. Александров, С.А. Мокрушина. ФТП, 52 (6), 637 (2018).

[8] P. Fazan, M. Dutoit, C. Martin, M. Ilegems. Solid-State Electron., 30, 829 (1987).

[9] J.F. Zhang, S. Taylor, W. Eccleston. J. Appl. Phys., 71 (2), 725 (1992).

[10] D.J. Di Maria, E. Cartier, D. Arnold. J. Appl. Phys., 73, 3367 (1993).

[11] C. Chen, W.L. Wilson, M.Smayling. J. Appl. Phys., 83 (7), 3898 (1998).

[12] C.C. Hsu, S.C.S. Pan, C.-T. Sah. J. Appl. Phys., 58 (3), 1326 (1985).

[13] H. Uchida, T. Ajioka. Appl. Phys. Lett., 51 (6), 433 (1987). 
[14] M.M. Heyns, D.K. Rao, R.F. Keersmaecker. Appl. Surf. Sci., 39, 327 (1989).

[15] S. Ogawa, N. Shiono, M. Shimaya. Appl. Phys. Lett., 56 (14), 1329 (1990).

[16] I.C. Chen, S. Holland, C. Hu. J. Appl. Phys., 61 (9), 4544 (1987).

[17] V.J. Kapoor, F.G. Feigl, S.R. Butler. J. Appl. Phys., 48, 739 (1977).

[18] F.J. Feigl, D.R. Young, D.J. DiMaria, S. Lai, J. Calise. J. Appl. Phys., 52, 5665 (1981).

[19] А.М. Емельянов. ФТП, 52, 1060 (2010).

[20] M. Aslam, R. Singh, P. Balk. Phys. Status Solidi A, 84, 659 (1984).

[21] P. Balk, M. Aslam, D.R. Young. Solid-State Electron., 27, 709 (1984).

[22] B.E. Deal, E.L. Mac Kenna, P.L. Castro. J. Electrochem. Soc., 116, 997 (1969).

[23] Ю.В. Федорович, Л.К. Думиш. ФТП, 6, 2321 (1972).

[24] P.J. Chen, R.M. Wallance. J. Appl. Phys., 86, 2237 (1999).

[25] Y. Nissan-Cohen, J. Shappir, D. Frohman-Bentchkowsky. J. Appl. Phys., 60 (6), 2024 (1986).

[26] W.D. Zhang, J.F. Zhang, M.J. Lalor, D.R. Burton, G. Groeseneken, R. Degraeve. Semicond. Sci. Technol., 18, 174 (2003).

[27] M. Aslam. IEEE Trans. Electron. Dev., 34, 2535 (1987).

Редактор Г.А. Оганесян

\section{Accumulation of charges in MOS-structures with polysilicon gate at tunnel injection}

O.V. Aleksandrov, A.N. Ageev, S.I. Zolotarev

St. Petersburg State Electrotechnical University „LETI“, 197376 St. Petersburg, Russia

Abstract Accumulation of charges in MOS-structures with doped and undoped polysilicon gates with $\mathrm{Al}$ and without $\mathrm{Al}$ contacts at tunnel injection of electrons from a gate and from a silicon substrate is studied. It is shown that independent of injection polarity the negative charge near a polysilicon gate, and the positive charge near a silicon substrate are collected. At large charges of injection near a silicon substrate also a negative charge is appeared. Results are described by means of numerical model in which formation of electronic traps at drawing $\mathrm{Al}$ contacts and generation of electronic traps at a recombination of free electrons with the trapped holes is considered. 